\title{
Girdin expression in cervical carcinoma and its role in the malignant properties of HeLa cells
}

\author{
PING JIANG ${ }^{1 *}$, YA-LI REN ${ }^{2 *}$, JIA-LIANG LI $^{3}$ and JUN LUO ${ }^{1}$ \\ ${ }^{1}$ The Key Laboratory of Geriatrics, Beijing Hospital and Beijing Institute of Geriatrics, Ministry of Health, Beijing 100730; \\ ${ }^{2}$ Laboratory of Electron Microscopy, Peking University First Hospital, Beijing 100034; \\ ${ }^{3}$ Clinical Laboratory, Fuda Cancer Hospital, Guangzhou, Guangdong 510665, P.R. China
}

Received May 26, 2014; Accepted May 20, 2015

DOI: $10.3892 / \mathrm{ol} .2016 .4250$

\begin{abstract}
Cervical cancer is a major cause of mortality in females worldwide, with the majority of cases reported in developing countries. The molecular mechanisms of this disease are unclear. However, increasing evidence indicates that the expression or overexpression of Girdin is associated with a poor prognosis in a variety of cancer types. Therefore, the aim of the current study was to evaluate the potential association between Girdin expression, and malignant properties of cervical cancer lesions and HeLa cells. Girdin protein expression was examined in 87 samples of cervical squamous cell lesions, including intraepithelial neoplasia (grades I and III) and invasive carcinoma, using immunohistochemical (IHC) staining. A short-hairpin RNA (shRNA) approach was employed to specifically suppress the expression of Girdin mRNA in HeLa cells in vitro, allowing the role of Girdin in a number of malignant properties to be evaluated. Girdin protein was observed in the cytoplasm of 79/87 (90.8\%) cervical cancer lesion specimens. However, no positive Girdin signals were identified in healthy cervical squamous epithelium samples. Furthermore, a significant correlation between Girdin expression and lesion grade was identified (Spearman's correlation coefficient, 0.566; $\mathrm{P}<0.001$ ). When Girdin was suppressed by Girdin shRNA, the rate of HeLa cell growth was significantly reduced in vitro $(\mathrm{P}<0.05)$. Additional analysis determined that Girdin was associated with serum-deprived induced HeLa apoptosis. Thus, patients with high-grade cervical cancer tumors exhibited a strong expression for Girdin, and Girdin appears to key in HeLa cell proliferation and serum-deprived induced apoptosis, supporting the hypothesis that Girdin may be important in the process of cervical carcinogenesis.
\end{abstract}

Correspondence to: Dr Ping Jiang, The Key Laboratory of Geriatrics, Beijing Hospital and Beijing Institute of Geriatrics, Ministry of Health, 1 Da Hua Road, Beijing 100730, P.R. China

E-mail: pingjiang@bjmu.edu.cn

*Contributed equally

Key words: cervical carcinoma, Girdin, HeLa cells, apoptosis

\section{Introduction}

Cervical cancer is the third most common malignancy in females globally, accounting for $8.8 \%$ of all cases of cancer. Furthermore, in 2008, 529,000 new cases and $\sim 274,000$ mortalities due to cervical cancer were reported worldwide (1). Approximately $80 \%$ of these cases occurred in individuals in developing countries (2).

Cervical cancer occurs in a multi-step process that involves the transformation of healthy cervical epithelium into preneoplastic cervical intraepithelial neoplasia (CIN) that eventually evolve into invasive cervical cancer cells $(3,4)$. It is well recognized that specific oncogenic human papilloma virus (HPV) is a primary etiological factor in cervical cancer $(5,6)$. However, only a small fraction of HPV-infected lesions progress to cervical cancer or its precursor lesion, cervical intraepithelial neoplasia (CIN), indicating that other genetic factors, including tumor-suppressor genes, proto-oncogenes and immunological factors, may be involved in the development of cervical cancer (7-9).

Girdin is a multi-functional protein with the ability to promote cell proliferation and migration (10-12). Girdin is located at the crossroad of $\mathrm{G}$ protein signaling and tyrosine kinase receptor signaling and, therefore, promotes the activation of a series of molecules, including $G$ protein, Akt and signal transducer and activator of transcription (STAT3) $(13,14)$. An increasing number of studies have demonstrated that Girdin is preferentially expressed in various malignant tissues, such as breast, colon and lung cancer, and glioblastoma (10,13,15-17). In specific types of tumor, for example glioblastoma, the expression of Girdin increases with the evolution of tumor progression and invasion (17). Furthermore, increased expression of Girdin appears to facilitate cell migration, and concomitant metastasis in breast and colon cancers $(10,16)$. Therefore, it has been suggested that the expression of Girdin may be predictive of outcome in breast and colorectal carcinoma $(16,18)$. However, the expression and function of Girdin in cervical carcinoma has yet to be investigated.

In the current study, the association between Girdin expression, and the various stages of intraepithelial neoplasia and squamous cell carcinoma was investigated. Furthermore, a short-hairpin RNA (shRNA) approach was used to selectively knock down the expression of Girdin mRNA in the cervical 
HeLa tumor cell line, and investigate its role in cell growth and apoptosis, two key characteristics in disease progression.

\section{Materials and methods}

Patient specimens. A total of 87 fresh cervical tissues were obtained from patients prior to undergoing chemo- or radiotherapy at Beijing Hospital, Ministry of Health (Beijing, China) between January 2010 and December 2012. The mean age of the 87 patients in the present cohort was 39.4 years (ra nge, 23-76 years). The samples comprised 66 invasive lesions, nine CIN I lesions and 12 CIN III lesions according to the International Federation of Gynecology and Obstetrics (19). In addition, five healthy cervical tissue biopsies were used as controls. The invasive lesion samples were obtained during radical hysterectomy and the CIN samples were obtained during cervical cone biopsy. The diagnostic criteria used were: Invasive lesions were defined as those that broke through the basement membrane and infiltrated to a depth of $>5 \mathrm{~mm}$; samples with cells representing atypical hyperplasia confined to the superficial one-third of the cervical epithelia were diagnosed as CIN I; and lesions involved in the full epithelia demonstrating no invasiveness were diagnosed as CIN III.

The present study was approved by the Ethics Committee of the Beijing Hospital (Beijing, China) and adhered to the tenets of the Declaration of Helsinki. Written informed consent was obtained from all the donors.

Immunohistochemistry. Endogenous expression of Girdinprotein was evaluated on 4- $\mu \mathrm{m}$, paraffin-embedded, serial sections of cervical tissues using rabbit polyclonal IgG anti-human Girdin antibody (\#sc-133371; Santa Cruz Biotechnology, Inc.) or control IgG, as previously described (10). Immunohistochemisty was performed using standard techniques. Antigen retrieval was performed with microwave treatment in a $0.01 \mathrm{~mol} / \mathrm{l}$ citrate buffer (pH 6.0) at $95^{\circ} \mathrm{C}$ for $10 \mathrm{~min}$. Girdin immunostaining was examined by counting $\geq 500$ cells in five random high power fields from each specimen using a Eclipse 80i light microscope (Nikon Corporation, Tokyo, Japan), as previously described (15). After counting, Girdin expression was semiquantitatively classified according to the proportion of immunoreactive cancer cells in the cytoplasm, as follows: $0,<1 \%$ of cells; $1+, \geq 1$ to $<10 \%$ of cells; $2+, \geq 10$ to $<50 \%$ of cells; and $3+, \geq 50 \%$ of cells.

Cell culture and proliferation assay. The human cervical squamous cell carcinoma line HeLa was maintained in culture medium (DMEM supplemented with $10 \%$ fetal bovine serum). HeLa cells (ScienCell Research Laboratories, Carlsbad, CA, USA) were transfected with Girdin shRNA (Invitrogen Life Technologies, Carlsbad, CA, USA) or control shRNA, as previously described by Jiang et al (10), and then seeded $\left(2 \times 10^{4}\right.$ cells) in 35-mm Petri dishes. After 24, 48 and $72 \mathrm{~h}$ incubation in culture medium, the cells were trypsinized, stained with $0.4 \%$ trypan blue (Yi San Biotechnology Co., Ltd., Shanghai, China), and counted using a hemocytometer (Qiujing, Inc, Zhejiang, China).

Apoptosis detection. Cell apoptosis was determined using Hoechst 33342 staining. All the steps were performed according to the manufacturer's instructions.
Western blot analysis. Samples were separated by $8 \%$ SDS-PAGE. Proteins were transferred to nitrocellulose membranes, blocked in 3\% skim milk in phosphate buffered saline and $0.05 \%$ Tween 20 , incubated with primary antibody (polyclonal rabbit IgG anti-human Girdin antibody; Santa Cruz Biotechnology, Inc.; \#sc-133371; dilution, 1:100), and detected with horseradish peroxidase-conjugated polyclonal goat anti-rabbit secondary antibody (\#P-0448; Dako, Glostrup, Denmark; dilution, 1:5,000). Immunoreactive bands were visualized using enhanced chemiluminescence detection reagents (Applygen Technologies Inc., Beijing, China).

Statistical analysis. Data were analyzed using SPSS statistical software (version 13.0; SPSS, Inc., Chicago, IL, USA). Differences between various groups were compared using a $\chi^{2}$ test, Fisher's exact test or one-way analysis of variance (ANOVA), where appropriate. The correlation between Girdin protein expression levels and the grade of lesion was determined by performing a Spearman's rank correlation test. The intensity of western blotting bands were analyzed by using Image-Pro Plus software, version 6.0. The level of Girdin expression and apoptotic cells were analyzed in triplicate. Furthermore, a t-test was used to detect the difference in cell migration and invasion. $\mathrm{P}<0.05$ was considered to indicate a statistically significant difference.

\section{Results}

Girdin protein expression in cervical cancer lesions. Girdin protein expression was observed in the cytoplasm of $79 / 87(90.8 \%)$ cervical cancer lesion specimens. However, no positive signal was identified in the five healthy cervical squamous epithelium samples (Table I; Fig. 1). In comparison to the negative staining observed in healthy cervical epithelial cells (Fig. 1A), all cases of invasive carcinoma expressed Girdin protein and positive Girdin protein signals were observed in 13/21 identifiable pre-malignant lesions (Table I). Specifically, Girdin was expressed in the basal and parabasal layers of CIN I samples ( $n=4$; Fig. 1B) and in the superficial layers of CIN III samples ( $n=9$; Fig. 1C). A staining degree of $3+$ was not observed in any of the CIN cases but was observed in eight cases of invasive carcinoma. Furthermore, moderate (2+) and intense (3+) staining for Girdin was detected in one (11.1\%) case of CIN I, three (25.0\%) cases of CIN III, and 50 (75.7\%) cases of invasive carcinoma (Table I). Statistical analysis of the expression of Girdin protein indicated a significant difference between the three grades of cervical cancer lesion (one-way ANOVA, F-value $=22.976$; Spearman's correlation coefficient, 0.566; $\mathrm{P}<0.001$; data not shown).

Girdin is essential for proliferation and serum-deprived induced apoptosis of HeLa cells. shRNA methodology was used to examine the potential role of endogenous Girdin expression in HeLa cells, as previously described by Jiang et al (10). The Girdin-specific shRNA targets and control shRNA targets were transfected into HeLa cells. After $48 \mathrm{~h}$ of transfection, western blot analysis demonstrated that Girdin protein expression was suppressed in the Girdin shRNA group compared with the control (Fig. 2A). Cell proliferation was detected at 24,48 and $72 \mathrm{~h}$ using 
Table I. Expression of Girdin in 87 cases of cervical squamous cell carcinoma using immunohistochemistry.

\begin{tabular}{llrrrr}
\hline & \multicolumn{3}{c}{ Degree of Girdin staining } & \\
\cline { 2 - 4 } Lesion grade & $0, \mathrm{n}(\%)$ & $1+, \mathrm{n}(\%)$ & $2+, \mathrm{n}(\%)$ & $3+, \mathrm{n}(\%)$ & Total patients, $\mathrm{n}(\%)$ \\
\hline Cervical intraepithelial neoplasia I & $5(55.6)$ & $3(33.3)$ & $1(11.1)$ & $0(0.0)$ & $9(100.0)$ \\
Cervical intraepithelial neoplasia III & $3(25.0)$ & $6(50.0)$ & $3(25.0)$ & $0(0.0)$ & $12(100.0)$ \\
Invasive squamous cell carcinoma & $0(0.0)$ & $16(24.2)$ & $42(63.6)$ & $8(12.1)$ & $66(100.0)$ \\
\hline
\end{tabular}
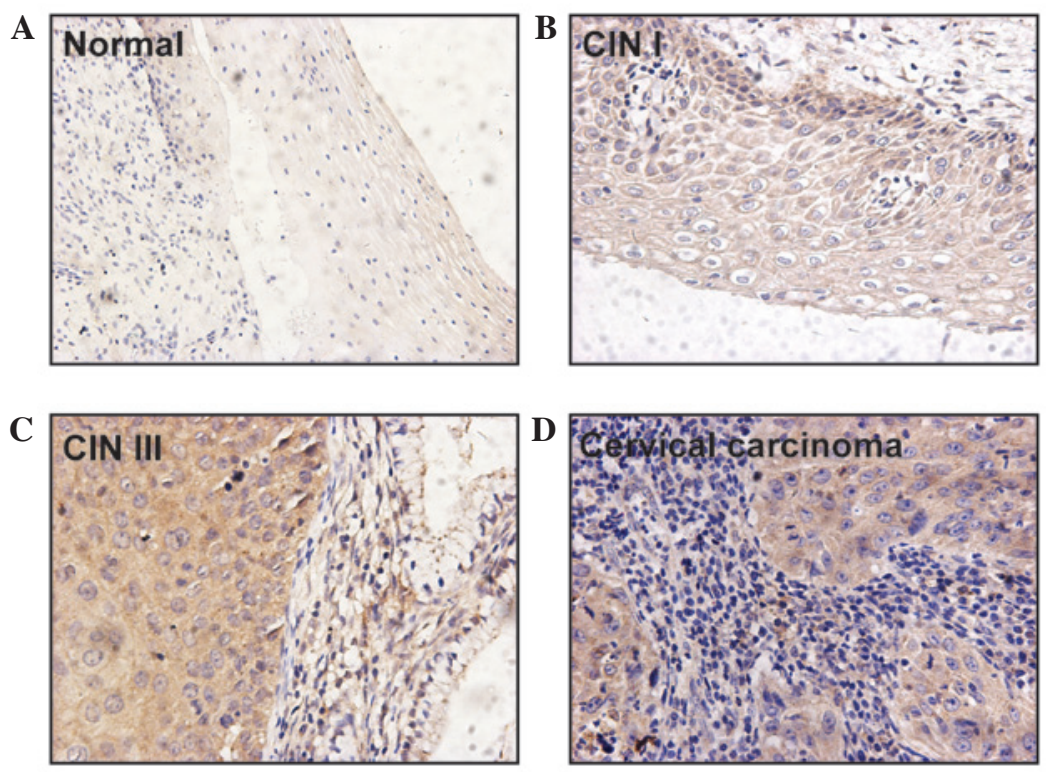

Figure 1. Strong immunohistochemical staining for Girdin in CIN and invasive cervical carcinoma samples. (A) Negative Girdin signals were identified in healthy epithelial cells. Positive staining was observed (B) in basal cells with atypical hyperplasia in CIN I, (C) in the superficial layer of CIN III and (D) in cancer cells of invasive lesions (magnification, $\mathrm{x} 400$ ). CIN, cervical intraepithelial neoplasia.

A

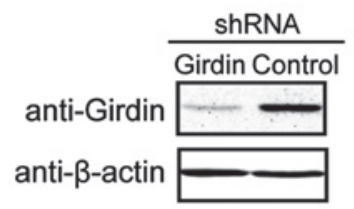

C

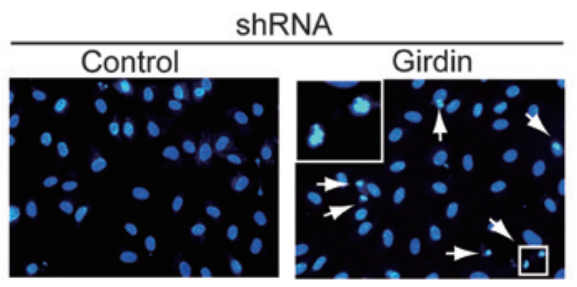

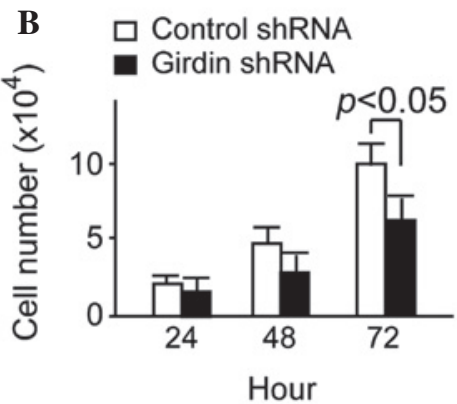

D

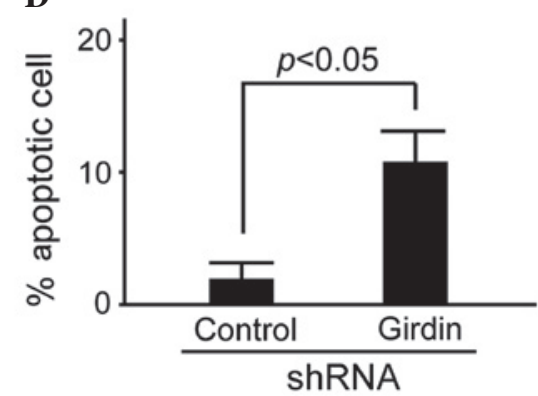

Figure 2. Girdin regulates cell proliferation and apoptosis in HeLa cells. (A) Western blot analysis indicated that Girdin was suppressed in the Girdin shRNA group but not in the control after $48 \mathrm{~h}$ of transfection. (B) Cell proliferation detected by trypan blue staining indicated that Girdin shRNA caused significant attenuation of proliferation in HeLa cells at $72 \mathrm{~h}(\mathrm{P}<0.05)$. (C and D) Apoptosis detected by Hoechst 33342 staining indicated that more apoptosis occurred in the Girdin shRNA group compared with the control.(C) Arrows and enlarged square indicate apoptotic cells. shRNA, short-hairpin RNA. 
trypan blue staining. It was identified that Girdin shRNA caused significant attenuation of HeLa cell proliferation at 72 h $(\mathrm{P}<0.05$; Fig. 2B).

Under normal conditions, almost no apoptosis was observed in Girdin-suppressed HeLa cells (data not shown). However, a large number of apoptotic cells was observed in the Girdin-suppressed HeLa cells when they were cultured in serum-deprived medium for $48 \mathrm{~h}$. By contrast, the control HeLa cells exhibited little apoptosis (Fig. 2C). A significant difference was observed between the proportion of apoptotic cells in the control and Girdin shRNA groups ( $\mathrm{P}<0.05$; Fig. 2D).

\section{Discussion}

Increasing evidence indicates that Girdin promotes cell motility in epithelial and endothelial cells $(10,20)$. As a type of actin-binding protein, Girdin is required for lamellipodia formation as it recruits actin to the leading edge for cell motility (10). Furthermore, it was reported that Girdin is essential for cell proliferation (11-13). A number of reports have demonstrated that Girdin promotes metastasis in breast carcinoma and colorectal carcinoma $(16,18)$. Natsume et al $(17)$ recently identified that Girdin is essential for glioblastoma invasion. The aforementioned studies indicate that Girdin is pivotal for the development of epithelium-derived cancer cells. In the present study, it was identified that Girdin protein is highly expressed in pre-malignant and malignant cervical carcinoma. Notably, a strong expression of Girdin was exclusively identified in the invasive lesions, while a negative or weak expression was detected in the pre-malignant lesions. In consideration of the current data, it is suggested that Girdin may promote the progression of cervical cancer lesions and is important for cancer invasion. This conclusion is additionally supported by the data from the present study, which demonstrated that Girdin mRNA is essential for HeLa cell proliferation.

Immunoexpression of Girdin has been recognized as a predictor for poor survival in specific malignancies. However, to the best of our knowledge, its predictive role has yet to be reported in cervical carcinomas. In the present study, immunohistochemical analysis was performed to identify Girdin protein expression in $90.8 \%$ of cervical squamous cell lesions. In addition, the expression of Girdin significantly correlated with the stage of the lesion. Although the current results indicate that the expression of Girdin contributes to a poor prognosis, the mechanism has yet to be sufficiently clarified in cervical cancer.

Thus far, the role of Girdin in apoptosis remains unclear. For example, Anai et al (21) reported that COS-7 cells expressing Akt and Girdin exhibit increased levels of apoptosis and that cells expressing Girdin alone exhibited little apoptosis. However, in the present study, it was observed that shRNA-induced depletion of Girdin induces apoptosis under starvation conditions. Considering that the Akt signal was inactive under the condition of serum deprivation, it is proposed that Girdin depletion and Akt inactivation cooperate to contribute to HeLa cell apoptosis. However, the detailed mechanisms and physiological significance require additional investigation.

Aberrant activation of STAT3 has been demonstrated a dominant association with carcinogenesis, and appears to promote cell cycle progression, cell proliferation and oncogenic transformation (22). A recent study identified that positive staining for phosphorylated STAT3 was observed in greater than half of the cervical carcinoma cases $(56.8 \%)$ investigated, and was significantly correlated with lymph node metastasis, lymph vascular space invasion and a large tumor diameter in cervical carcinoma (23). Notably, Girdin is a direct target of STAT3. Immunohistochemical analysis of breast carcinoma samples identified a significant correlation between STAT3 activation and elevated Girdin expression. Furthermore, Girdin positively autoregulates its own transcription by enhancing STAT3 activation (14). However, whether a similar interaction exists between STAT3 and Girdin in cervical lesions merits further investigation.

In conclusion, the findings of the present study indicate that Girdin protein is highly expressed in cervical cancer. Furthermore, Girdin mRNA appears to be essential for cell proliferation and apoptosis in HeLa cells. Therefore, Girdin may act as a prospective diagnostic biomarker in cervical cancer associated with disease stage and tumor grade.

\section{Acknowledgements}

The present study was supported by National Natural Science Foundation of China (grant no.81072172); the China Postdoctoral Science Foundation special funding (grant no. 201104043); and the Scientific Research Foundation for the Returned Overseas Chinese Scholars, State Education Ministry (grant no. jws1433).

\section{References}

1. Ferlay J, Shin HR, Bray F, Forman D, Mathers C and Parkin DM: Estimates of worldwide burden of cancer in 2008: GLOBOCAN 2008. Int J Cancer 127: 2893-2917, 2010.

2. Pisani P, Bray F and Parkin DM: Estimates of the world-wide prevalence of cancer for 25 sites in the adult population. Int J Cancer 97: 72-81, 2002.

3. Richart RM: A modified terminology for cervical intraepithelial neoplasia. Obstet Gynecol 75: 131-133, 1990.

4. Creasman WJ: Preinvasive disease of the cervix. In: Clinical Gynecologic Oncology. DiSaia PJ and Creasman WJ (eds). 6th edition. CV Mosby, St. Louis, MO, pp1-34, 2002.

5. Basu P and Chowdhury D: Cervical cancer screening \& HPV vaccination: a comprehensive approach to cervical cancer control. Indian J Med Res 130: 241-246, 2009.

6. Saleem A, Tristram A, Fiander A and Hibbitts S: Prophylactic HPV vaccination: a major breakthrough in the fight against cervical cancer? Minerva Med 100: 503-523, 2009.

7. Magnusson PK, Sparén P and Gyllensten UB: Genetic link to cervical tumours. Nature 400: 29-30, 1999.

8. zur Hausen H: Papillomaviruses and cancer: from basic studies to clinical application. Nat Rev Cancer 2: 342-350, 2002.

9. Georgieva S, Iordanov V and Sergieva S: Nature of cervical cancer and other HPV-associated cancers. J BUON 14: 391-398, 2009.

10. Jiang P, Enomoto A, Jijiwa M, et al: An actin-binding protein Girdin regulates the motility of breast cancer cells. Cancer Res 68: 1310-1318, 2008.

11. Ghosh P, Beas AO, Bornheimer SJ, et al: A Gai-GIV molecular complex binds epidermal growth factor receptor and determines whether cells migrate or proliferate. Mol Biol Cell 21: 2338-2354, 2010.

12. Mao JZ, Jiang P, Cui SP, et al: Girdin locates in centrosome and midbody and plays an important role in cell division. Cancer Sci 103: 1780-1787, 2012.

13. Weng L, Enomoto A, Ishida-Takagishi M, Asai N and Takahashi M: Girding for migratory cues: roles of the Akt substrate Girdin in cancer progression and angiogenesis. Cancer Sci 101: 836-842, 2010.

14. Dunkel Y, Ong A, Notani D, Mittal Y,Lam M, Mi X and Ghosh P: STAT3 protein up-regulates $\mathrm{G} \alpha$-interacting vesicle-associated protein (GIV)/Girdin expression, and GIV enhances STAT3 activation in a positive feedback loop during wound healing and tumor invasion/metastasis. J Biol Chem 287: 41667-41683, 2012. 
15. Ling Y, Jiang P, Cui SP, et al: Clinical implications for girdin protein expression in breast cancer. Cancer Invest 29: 405-410, 2011.

16. Garcia-Marcos M, Jung BH, Ear J, Cabrera B, Carethers JM and Ghosh P: Expression of GIV/girdin, a metastasis-related protein, predicts patient survival in colon cancer. FASEB J 25: 590-599, 2011

17. Natsume A, Kato T, Kinjo S, et al: Girdin maintains the stemness of glioblastoma stem cells. Oncogene 31: 2715-2724, 2012.

18. Liu C, Zhang Y, Xu H, Zhang R, Li H, Lu P and Jin F: Girdin protein: a new potential distant metastasis predictor of breast cancer. Med Oncol 29: 1554-1560, 2012.

19. Benedet JL, Bender H, Jones H 3rd, Ngan HY and Pecorelli S FIGO staging classifications and clinical practice guidelines in the management of gynecologic cancers. FIGO Committee on Gynecologic Oncology. Int J Gynaecol Obstet 70:209-262, 2000.
20. Kitamura T, Asai N, Enomoto A, Maeda K, Kato T, Ishida M, Jiang P, Watanabe T, Usukura J, Kondo T, et al: Regulation of VEGF-mediated angiogenesis by the Akt/PKB substrate Girdin. Nat Cell Biol 10: 329-337, 2008.

21. Anai M, Shojima N, Katagiri H, et al: A novel protein kinase B (PKB)/AKT-binding protein enhances PKB kinase activity and regulates DNA synthesis. J Biol Chem 280: 18525-18535, 2005.

22. Kim DJ, Chan KS, Sano S and Digiovanni J: Signal transducer and activator of transcription 3 (stat3) in epithelial carcinogenesis. Mol Carcinog 46: 725-731, 2007.

23. Takemoto S, Ushijima K, Kawano K, et al: Expression of activated signal transducer and activator of transcription-3 predicts poor prognosis in cervical squamous-cell carcinoma. Br J Cancer 101: 967-972, 2009. 